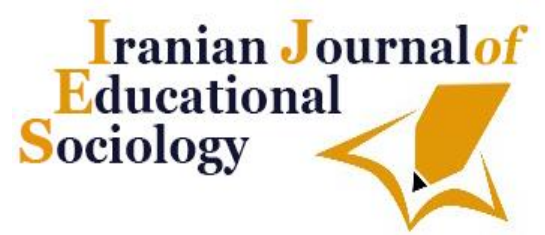

Iranian Journal of Educational Sociology

(Interdisciplinary Journal of Education)

Available online at: $\underline{\text { http://www.iase-idje.ir/ }}$

Volume 4, Number 2, June 2021

\title{
Explaining the Model of Social Responsible Organization from the Perspective of Academic Experts
}

\author{
Hossein Farzad ${ }^{1}$, Mojtaba Rafiei ${ }^{2 *}$, Mohammad Javad Hozoori ${ }^{3}$, Ali Farrahi ${ }^{4}$ \\ 1. PhD student in Public Administration, Payame Noor University, Tehran, Iran. \\ 2. Associate Professor, Department of Public Administration, Payame Noor University, Tehran, Iran. \\ 3. Associate Professor, Department of Public Administration and Tourism, Payame Noor University, Tehran, Iran. \\ 4. Professor, Imam Hossein University, Tehran, Iran
}

Article history:

Received date: 2020/12/15

Review date: $2021 / 04 / 02$

Accepted date: 2021/04/07

\section{Keywords:}

Socially Responsible Organization, People, Goals, Technology, Academic Experts

\begin{abstract}
Purpose: The purpose of this study was to design a model of social responsibility and explain the framework of social responsibility based on the ISO 26000 standard in order to achieve sustainable development from the perspective of academic experts.
\end{abstract}

Methodology: This research is applied in terms of purpose and is descriptive-survey in terms of data collection. The statistical population in this study is faculty members and university experts, who are equal to 1377 people, according to Cochran's formula, 301 faculty members and university experts have been selected by stratified sampling. Also, in the present study, based on the research hypotheses, a researcher-made questionnaire was used to collect data. In this study, Cronbach's alpha coefficient method was used to determine the reliability coefficient. The combined reliability and reliability of each of the research components were calculated. The results indicate the reliability of the measurement tool.

Findings: The results of research hypotheses indicate that people, goals, technology, organizational structure and environment are the dimensions of socially responsible organization and the components of goals, technology, structure, people and environment have a positive effect on socially responsible organization in Tehran Municipality.

Conclusion: The results of this study showed that people, goals, technology, structure and environment have a direct and significant impact on socially responsible organization.

\footnotetext{
Please cite this article as: Farzad H, Rafiei M, Hozoori M J, Farrahi A. (2021), Explaining the Model of Social Responsible Organization from the Perspective of Academic Experts, Iranian Journal of Educational Sociology. 4(2): 71 - 82.
}

* Corresponding author: mjtb_rf@yahoo.com 


\section{Introduction}

Technology According to Liden, appropriate technology not only includes the organization's ability to perform tasks effectively, but also improves the system's ability to grow, prosper, and prosper. In a good technology, there are literate and committed managers and conscientious employees with high morale who love their work and are effective and useful people who are the dynamics of the organization. Organizations with healthy technology can emerge as living and dynamic organisms in the environment and grow by providing the necessary and sufficient facilities, and by providing healthy and valuable services to meet environmental needs and facilitate the growth process, and the prosperity of society (Sheikhi, 2015).

Also, another effective pillar in a responsible organization is the role of technology in accountability. (Majidi Ghahroudi and Javadieh, 2011) Also, informal communication between employees and managers, especially regarding goals, policies and practices in the organization, can increase organizational responsibility. According to Armichel (1990), organizations will be effective if they have the necessary technology in addition to other necessary conditions (Saedi, et al, 2014). The role of the environment in a responsible organization means that a healthy organization while being stable and surviving in the environment, in the long run is sufficiently adapted to it, has the necessary ability to maintain and survive in the environment, and expands (Tawfiqi, et al, 2015). Responsible organization plays an important role in the environmental dynamics of the organization, and should be considered in accordance with the pillars of the environment, which will include environmental dynamics, environmental awareness, environmental change and environmental responsiveness. Researchers have also conducted studies on the development of accountability and its effects on increasing or decreasing organizational performance (Ferrell et al, 2020).

Parch \& Baughman consider an organization responsible for having the right work environment, the ability to maintain and respond to tasks, especially in relation to the environment and society (Kunda, et al, 2019). Important factors related to social responsibility are the importance of management reputation and reputation, employee attraction, competition, investor relations, legal responsibilities and legal requirements, cost efficiency and quality, respectively. Dund (Kaptein, et al, 2017). Ferrell, et al (2020) stated in a study that it is important to understand the relative importance of business ethics and social responsibility in determining attitudes. Kunda, et al (2019) stated in a study that active employees are very concerned about their organizational, legal, social, and social activities, which commits them to extra-role behaviors. Ceil (2016) in the study of social responsibility of organizations and employees has concluded that social responsibility can increase the performance of employees and ultimately leads to an increase in their organizational commitment. Kavaliauskè and Stancikas (2014) revealed in a study that consumers prefer social responsibility, although they generally accepted and endorsed socially and environmentally responsible measures.

Yousefi \& Fattahi (2020) stated that the general expectations of social responsibility have a positive and significant effect on the response to social responsibility behavior in Behpak Behshahr. Ghavami, Jafari Samimi (2020) in a study showed that business ethics has a significant positive effect on attitude. Aghighi and Torabian (2019) stated in a study that understanding the concept of business ethics requires paying attention to the core values of individuals, comprehensive knowledge of the causes of ethical and immoral behaviors, and taking measures to establish and maintain an ethical system in organizations. Khajavand, et al (2016) stated in a study that attention to the pillars of responsibility in city management and especially managers who will play a significant role in the development or non-development of the city. Hajiha and Sarfaraz (2014) in a study show that social responsibility has an inverse and significant relationship with equity costs. Shafei and Azizi (2013) in an article showed that the elements of social and economic consequences of accountability have the highest score for measuring this concept in universities.

Therefore, the purpose of this study is to design and explain the framework of social responsibility model based on ISO 26000 standards from the perspective of academic experts in order to achieve sustainable development. Based on this, in this research we seek to find the question that what are the 
variables affecting the socially responsible organization based on the ISO 26000 standard, and what is the model of the socially responsible organization in Tehran Municipality?

According to the mentioned contents, the following conceptual model can be considered for this research:

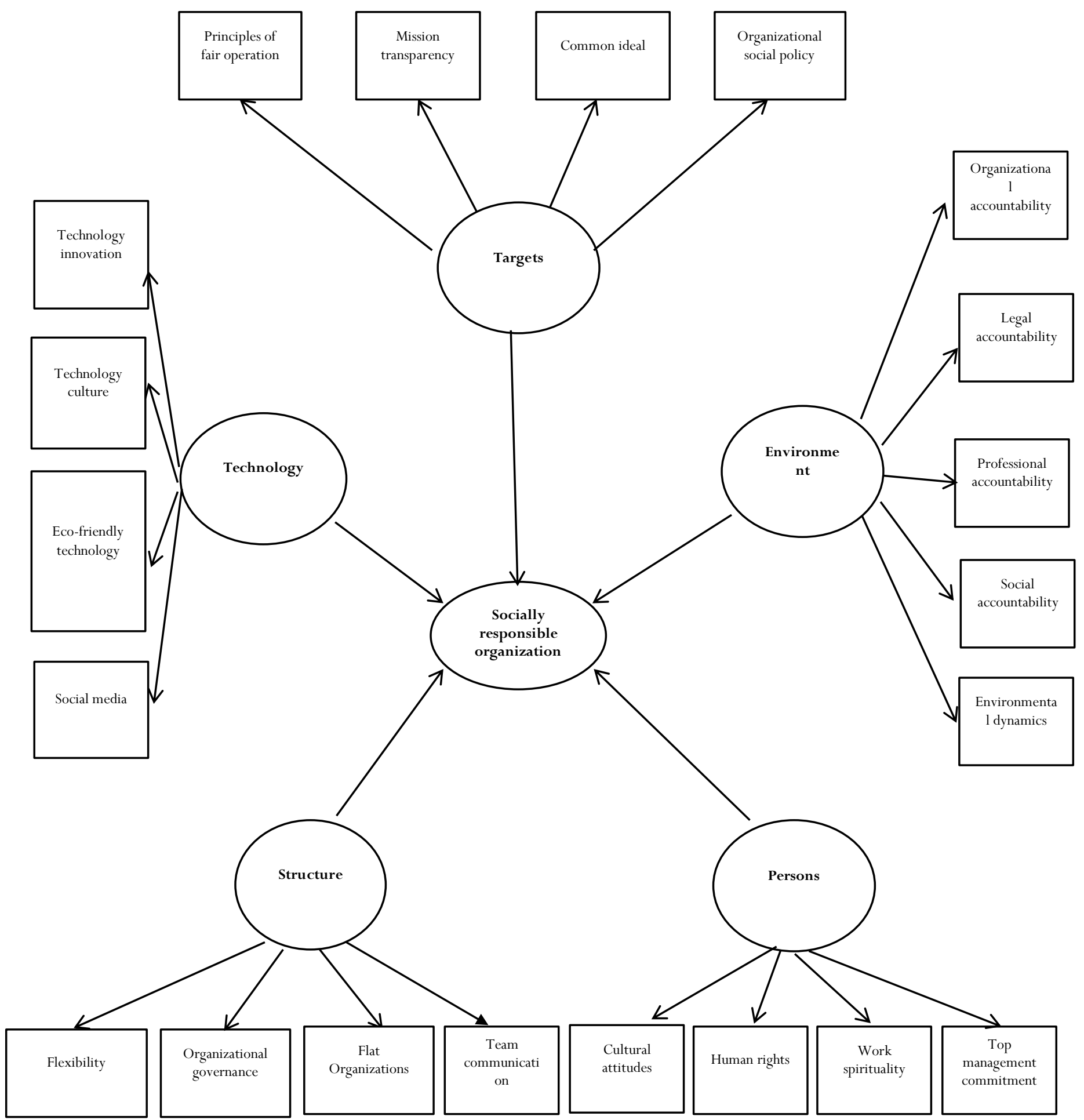

Figure1. Final model of the research 
It is necessary to mention that all twenty factors used in the design of the model were extracted from the theoretical foundations and a review of the research literature (Figure 1). The five-component template has been rearranged. Therefore, according to the conceptual model, the research hypotheses were presented as follows: 1) Objectives have a significant impact on socially responsible organization in Tehran Municipality. 2) Technology has a significant impact on socially responsible organization in Tehran Municipality. 3) The structure has a significant impact on socially responsible organization in Tehran Municipality. 4) People have a significant impact on socially responsible organization in Tehran Municipality. 5) The environment has a significant impact on socially responsible organization in Tehran Municipality.

\section{Methodology}

This research was applied in terms of purpose and descriptive-survey in terms of data collection. The statistical population in this study was faculty members and university experts in Tehran Municipality, which was equal to 1377 people. According to Cochran's formula, 301 people were selected by stratified sampling from northeast, northwest, southwest, center and southeast. . Finally, the statistical sample members of this study included 301 faculty members and university experts in Tehran Municipality, whose conditions include familiarity with the field of sociology and especially the field of socially responsible organization and having a master's degree, doctoral and doctoral student Or the mayors of the 22 districts of Tehran, deputies, deputies, heads of departments and mayors of districts with teaching experience at the university. The most important reasons for choosing this statistical community is the consistency and thematic relevance of the socially responsible organization based on the ISO 26000 standard with the goals of the organization, which is one of the strategic organizations in Iran. Also, the high level of knowledge of managers, some of whom are respected faculty members, and have sufficient information about socially responsible organization and aspects related to this field. Also in the present study, based on the research hypotheses, a researcher-made questionnaire was used to collect data. In this study, Cronbach's alpha coefficient method was used to determine the reliability coefficient. The value of combined reliability and the reliability of each component of the research were calculated, which indicates the reliability of the measurement tool. Also, divergent and convergent validity of the questionnaire was obtained, which showed the appropriate validity of the questionnaire. Similarly, causal relationships between independent and dependent variables, ie research hypotheses, were used using structural equation modeling using PLS3 software. Unlike Variance-based structural equation modeling, which evaluates the fit of a hypothetical model and thus estimates the model to explain, test, and validate theories, the PLS method is a predictive circuit and can be used as a theory explanation method to be gone.

\section{Findings}

The results of the analysis of demographic information of the statistical sample in this study, indicate that out of 301 people, 224 people are male, which includes $75 \%$ of the total sample and 77 people are women. Also, 42 people have doctoral studies, 89 people have doctoral students and 170 people have master's degrees. Also, 88 people are between 30 and 40 years old, 134 people are 40 to 50 years old and 79 people are 50 years old and older.

In performing heuristic factor analysis, one must first make sure that the available data can be used for analysis or not. Therefore, we first examine the appropriateness of the data for factor analysis. There are several ways to do this; including calculating the KMO value, which always fluctuates between 0 and 1 . Sampling adequacy can be ensured by using Bartlett test. Considering the KMO number which is equal to 0.827 and is greater than 0.7 and the significant number of Bartlett test which is equal to 0.000 and 
$(0.05 \mathrm{sig}<)$, it can be said that the data are suitable for performing factor analysis and the conditions Required.

Table1. Results of exploratory factor analysis test and determination of factor load for each component

\begin{tabular}{|c|c|c|c|c|c|c|c|c|}
\hline Dimensions & Component & $\begin{array}{l}\text { Latin } \\
\text { abbreviation }\end{array}$ & $\begin{array}{l}\text { Subscription } \\
\text { ratio }\end{array}$ & $\begin{array}{l}\text { The first } \\
\text { factor } \\
\text { load }\end{array}$ & $\begin{array}{l}\text { The } \\
\text { second } \\
\text { factor }\end{array}$ & $\begin{array}{l}\text { The } \\
\text { third } \\
\text { factor } \\
\text { load }\end{array}$ & $\begin{array}{l}\text { The } \\
\text { fourth } \\
\text { factor } \\
\text { load }\end{array}$ & $\begin{array}{l}\text { The } \\
\text { Fifth } \\
\text { factor } \\
\text { load }\end{array}$ \\
\hline \multirow[t]{4}{*}{ Targets } & $\begin{array}{l}\text { Mission } \\
\text { transparency }\end{array}$ & GLS1 & .813 & .061 & .884 & .064 & .101 & .118 \\
\hline & Common ideal & GLS2 & .781 & .134 & .849 & .121 & .026 & .166 \\
\hline & $\begin{array}{l}\text { Principles of fair } \\
\text { operation }\end{array}$ & GLS3 & .700 & .126 & .809 & .092 & .019 & .146 \\
\hline & $\begin{array}{l}\text { Organizational } \\
\text { social policy }\end{array}$ & GLS4 & .799 & .103 & .869 & .084 & .045 & .157 \\
\hline \multirow[t]{4}{*}{ Technology } & $\begin{array}{l}\text { Technology } \\
\text { innovation }\end{array}$ & TEC1 & .687 & .072 & .243 & .044 & .094 & .782 \\
\hline & $\begin{array}{l}\text { Technology } \\
\text { culture }\end{array}$ & TEC2 & .799 & .132 & .128 & .156 & .031 & .860 \\
\hline & $\begin{array}{l}\text { Eco-friendly } \\
\text { technology }\end{array}$ & TEC3 & .675 & .148 & .071 & .196 & .082 & .777 \\
\hline & social media & TEC4 & .818 & .207 & .173 & .038 & .027 & .862 \\
\hline \multirow[t]{4}{*}{ Structure } & $\begin{array}{l}\text { Team } \\
\text { communication }\end{array}$ & STR1 & .766 & .061 & .043 & .068 & .869 & -.005 \\
\hline & Flat structures & STR2 & .764 & .085 & .138 & -.024 & .858 & .036 \\
\hline & $\begin{array}{l}\text { Organizational } \\
\text { governance }\end{array}$ & STR3 & .655 & .113 & -.009 & -.024 & .799 & .053 \\
\hline & flexibility & STR4 & .881 & .076 & .016 & -.031 & .924 & .141 \\
\hline \multirow[t]{4}{*}{ Persons } & Cultural attitudes & PRS1 & .711 & .067 & .036 & .831 & .065 & .101 \\
\hline & $\begin{array}{l}\text { Top management } \\
\text { commitment }\end{array}$ & PRS2 & .828 & .122 & .118 & .891 & -.005 & .073 \\
\hline & human rights & PRS3 & .730 & .120 & .053 & .834 & -.059 & .119 \\
\hline & Work spirituality & PRS4 & .825 & .132 & .157 & .877 & -.017 & .115 \\
\hline \multirow[t]{5}{*}{ Environment } & $\begin{array}{l}\text { Organizational } \\
\text { accountability }\end{array}$ & ENV1 & .708 & .818 & .117 & .080 & .047 & .130 \\
\hline & $\begin{array}{l}\text { Legal } \\
\text { accountability }\end{array}$ & ENV2 & .814 & .878 & .055 & .051 & .069 & .179 \\
\hline & $\begin{array}{l}\text { Professional } \\
\text { accountability }\end{array}$ & ENV3 & .609 & .741 & .134 & .178 & .093 & .038 \\
\hline & $\begin{array}{l}\text { Social } \\
\text { accountability }\end{array}$ & ENV4 & .829 & .889 & .057 & .046 & .070 & .165 \\
\hline & $\begin{array}{l}\text { Environmental } \\
\text { dynamics }\end{array}$ & ENV5 & .612 & .757 & .089 & .122 & .100 & .078 \\
\hline
\end{tabular}

To check the model fit, we use the measurement model fit, the structural model fit, and the overall model fit. In order to evaluate the reliability of the research measurement model, we examine the factor load coefficients, Cronbach's alpha coefficients and the combined reliability. According to the data analysis algorithm in PLS, after measuring the factor loads of the questions, it is time to calculate and report Cronbach's alpha coefficients and combined reliability. The second criterion for examining the fit of measurement models is convergent validity, which examines the degree of correlation of each structure with its questions (indicators). The results are shown in the table below. 
Table2. The results of Cronbach's alpha criterion and the combined reliability of the latent variables of the research

\begin{tabular}{llllll}
\hline $\begin{array}{l}\text { Concealed } \\
\text { variables }\end{array}$ & sign & $\begin{array}{l}\text { Cronbach's alpha coefficient } \\
(\text { Alpha }>0.7)\end{array}$ & $\begin{array}{l}\text { Combined reliability coefficient } \\
(\mathrm{CR}>0.7)\end{array}$ & $\begin{array}{l}\text { Mean } \\
(\mathrm{AVE}>0.5)\end{array}$ \\
\hline Environment & ENV & 0.895 & 0.923 & 0.708 \\
\hline Targets & GLS & 0.902 & 0.931 & 0.773 \\
\hline Persons & PRS & 0.900 & 0.931 & 0.771 \\
\hline Structure & STR & 0.893 & 0.926 & 0.759 \\
\hline Technology & TEC & 0.879 & 0.917 & 0.734 \\
\hline
\end{tabular}

Considering that the appropriate value for Cronbach's alpha and the combined reliability is 0.7 and according to the findings of the above table, these criteria have adopted a suitable value for latent variables, it can be confirmed that the reliability of the research is appropriate. Considering that the appropriate value for AVE is 0.5 and in accordance with the findings of the table above, this criterion has adopted a suitable value for latent variables, thus confirming the appropriateness of the convergent validity of the research. We used the Fornell-Larker criterion to measure divergent validity. Since the values of the original diameter (AVE root) for each hidden variable are greater than the correlation of that variable with other hidden variables in the model, the divergent validity of the model is also confirmed.

To investigate the fit of the structural model in a study, the R2 coefficients are related to the latent endogenous (dependent) variables of the model. R2 is a criterion that indicates the effect of an exogenous variable on an endogenous variable and three values of $0.19,0.33$ and 0.67 are considered as criteria for weak, medium and strong values of R2. According to Figure 3, the value of R2 has been calculated for the endogenous structures of the research, which according to the three values of the criterion, can confirm the appropriateness of the fit of the structural model. To evaluate the fit of the general model, the GOF criterion is used, which three values of $0.01,0.25$ and 0.36 are introduced as weak, medium and strong values for GOF, This criterion is calculated using the following formula:

$$
G O F=\sqrt{\overline{\text { communalities }} \times \overline{R^{2}}}
$$

$\overline{\text { Communalitles }}$ : The average values of the latent variables of the research are obtained from the average

Table3. Communality rate and $\mathrm{R} 2$ research variables

\begin{tabular}{|c|c|c|c|}
\hline Concealed variables & sign & R2 & Communality \\
\hline Environment & ENV & & 0.714 \\
\hline Targets & GLS & & 0.773 \\
\hline Persons & PRS & & 0.774 \\
\hline Structure & STR & & 0.766 \\
\hline Technology & TEC & & 0.744 \\
\hline Socially responsible organization & CSR & 0.942 & 0.754 \\
\hline Communality & R2 & & GOF \\
\hline 0.754 & 0.942 & & 0.842 \\
\hline
\end{tabular}

Given the value obtained for GOF of 0.842 , a good fit of the overall model is confirmed. In this section, we test the research hypotheses using PLS software. 


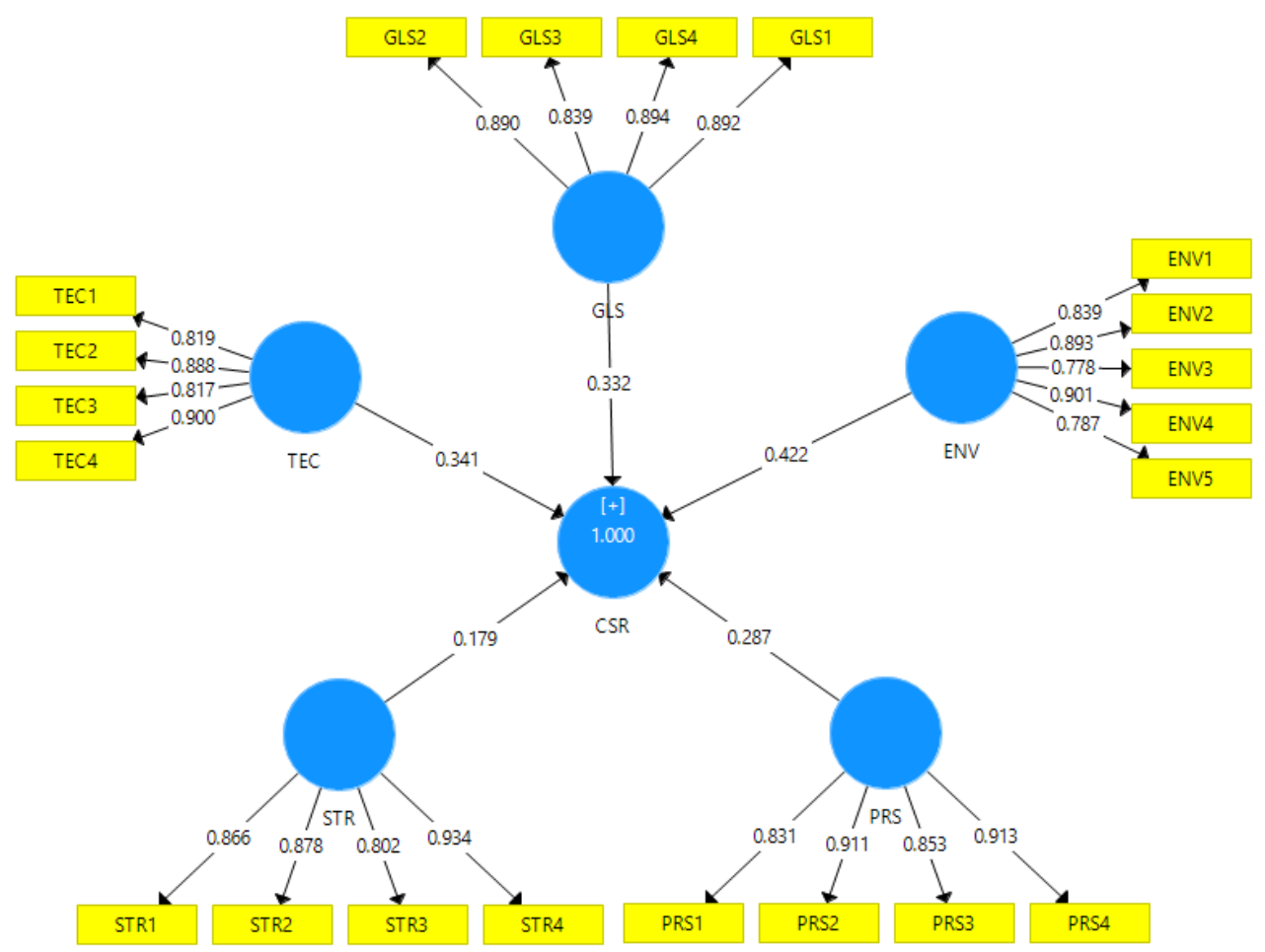

Figure2. Structural model of research with factor load coefficients

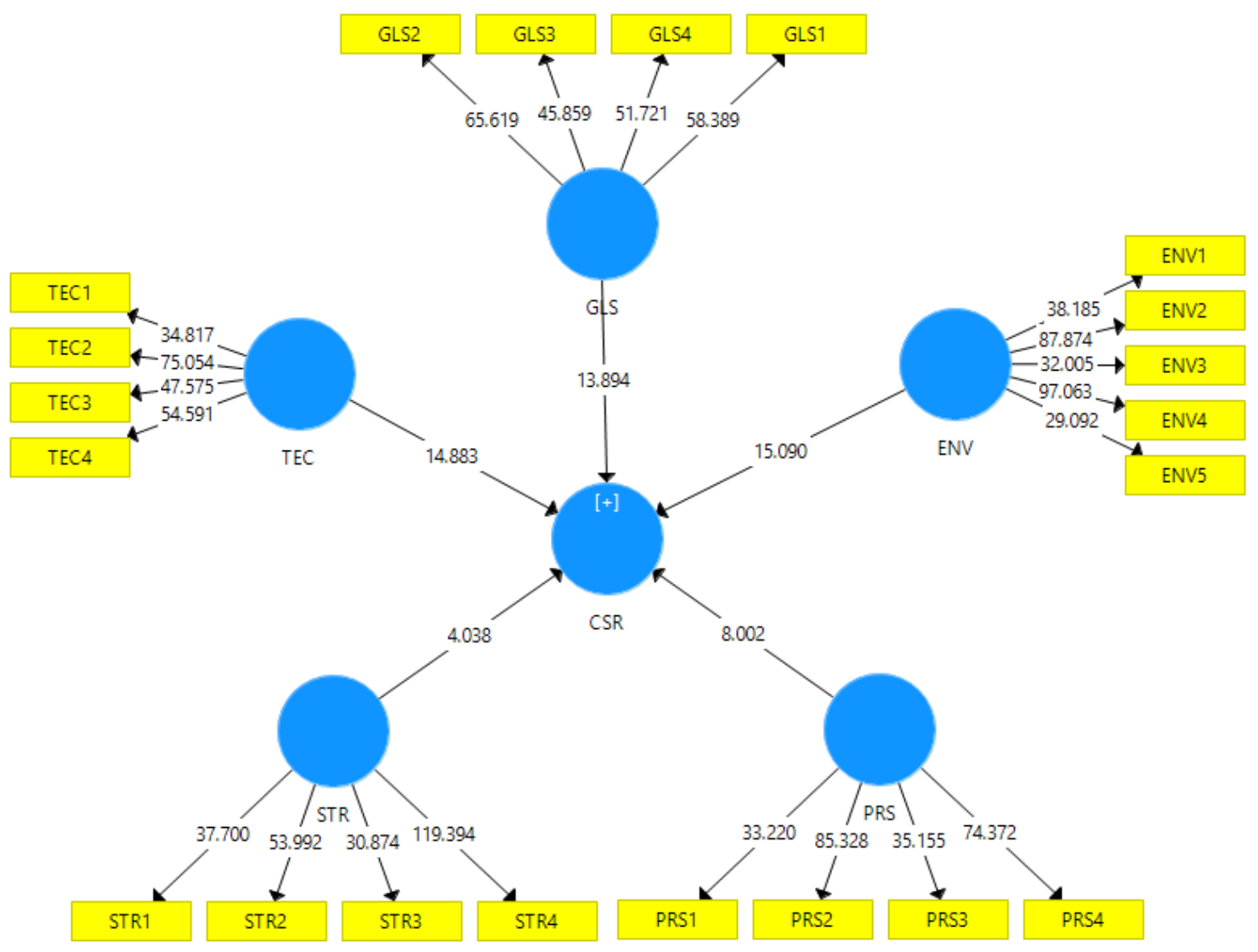

Figure3. Structural model of research with significant coefficients 
Hypothesis 1: Objectives have a significant effect on socially responsible organization in Tehran Municipality. According to Figures 2 and 3, it can be said that the standardized coefficient (path coefficient) is equal to $\beta=0.332$. And the coefficient of significance ( $t$-statistic) was equal to $t=13.894$ (more than the absolute value of 1.96), which shows that this effect is positive and significant. Therefore, Hypothesis $0 \mathrm{H}$ is rejected and Hypothesis $\mathrm{H} 1$ is confirmed and it can be concluded that the goals in the socially responsible organization have a significant positive effect on Tehran Municipality. Therefore, the first hypothesis will be confirmed.

Hypothesis 2: Technology has a significant effect on socially responsible organization in Tehran Municipality. According to Figures 2 and 3, it can be said that the standardized coefficient (path coefficient) is equal to $\beta=0.341$. And the coefficient of significance ( $t$-statistic) was equal to $t=14.883$, which shows that this effect is positive and significant. And it can be concluded that technology has a significant positive effect on socially responsible organization. Therefore, the second hypothesis will be confirmed.

Hypothesis 3: Structure has a significant effect on socially responsible organization in Tehran Municipality. According to Figures 2 and 3, it can be said that the standardized coefficient (path coefficient) is equal to $\beta=0.179$. And the significance coefficient ( $t$-statistic) was equal to $t=4.038$, which shows that this effect is positive and significant. And it can be concluded that the structure has a significant positive effect on socially responsible organization. Therefore, the third hypothesis will be confirmed.

Hypothesis 4: Individuals have a significant impact on socially responsible organization in Tehran Municipality. According to Figures 2 and 3, it can be said that the standardized coefficient (path coefficient) is equal to $\beta=0.287$. And the significance coefficient ( $\mathrm{t}$-statistic) was equal to $\mathrm{t}=8.002$, which shows that this effect is significant. And it can be concluded that individuals have a significant positive impact on socially responsible organization. Therefore, the fourth hypothesis will be confirmed.

Hypothesis 5: Environment has a significant effect on socially responsible organization in Tehran Municipality. According to Figures 2 and 3, it can be said that the standardized coefficient (path coefficient) is equal to $\beta=0.422$. And the significance coefficient ( $t$-statistic) was equal to $t=15.090$, which shows that this effect is positive and significant. Therefore, it can be concluded that the environment has a significant positive effect on socially responsible organization in Tehran Municipality. Therefore, the fifth hypothesis will be confirmed.

\section{Discussion}

The results of the first hypothesis of the research show that the goals in the socially responsible organization in Tehran Municipality have a significant positive effect. This result is consistent with the findings of other studies such as Rigoberto Parada (2016) whose main emphasis is on the behavior of a company and its owners when pursuing economic rationality (human economics) and social responsibility at the same time. Avram and Avasilcai (2014) indicate that most people's psychological belonging to organizations is in the shadow of membership and a positive image of it. They have shown that people enthusiastically share their gifts and possessions with the organization, and in return expect the organization to receive respect and establish organizational membership. Gifts and rewards refer to a strong belief and are considered a positive value in the organization, while respect reflects the belief that organizational membership is valuable in itself. Therefore, pride and respect cause a sense of commitment to the organization and increase responsibility.

The results of the second hypothesis of the research show that technology has a significant positive effect on socially responsible organization in Tehran Municipality. This result, along with the findings of other researches such as Karaye, et al (2014), also indicates a positive relationship between corporate social 
responsibility and corporate financial performance. Aslan and Şendoğdu (2012) also showed in their research that ethical leadership positively affects corporate social responsibility, and social responsibility, in turn, positively transforms corporate ethical values and ethical behaviors. But the findings of Hajiha and Sarfaraz (2014) also show that social responsibility has an inverse and significant relationship with equity costs. Therefore, by increasing the disclosure of social performance, managers reduce the rate of return expected by investors (equity costs), and bring lower financing costs for the company.

The results of the third hypothesis of the research show that the structure has a significant positive effect on socially responsible organization in Tehran Municipality. This finding, along with the findings of other research, including Hahn (2013), suggests guidance on social responsibility and helping different types of organizations to participate in sustainable development. Many companies lack a strategic approach to corporate social responsibility and instead follow unsystematic practices. The results of Barone, et al (2016) also indicate the relationship between employees' social responsibility and their job morale and motivation. Their findings also showed that political, cultural and institutional factors are effective in the relationship between corporate social responsibility and motivation.

The results of the fourth hypothesis of the research show that individuals have a significant positive effect on socially responsible organization in Tehran Municipality. This result, together with the findings of other researches such as Wahba and Elsayed (2015), also indicates the existence of a relationship between social responsibility and institutional investors. Also in this regard, Nasiri (2014) research showed that the level of organizational support, social responsibility and job performance of employees was above average and there is a positive and significant relationship between the level of organizational support and social responsibility and job performance in Hamadan Municipality. The research of Shafei and Azizi (2013) also shows that there is a significant difference in the level of social responsibility in the studied universities compared to other top universities in the world. The results of the fifth hypothesis of the research show that the environment at the level of $95 \%$ has a significant positive effect on socially responsible organization in Tehran Municipality. This result, along with the findings of other researches such as Alwani and Ahmadi (2013), indicate that management should include the expression of a sense of citizenship in its performance. (Alvani and Ahmadi, 2013)

Also today, public administration is considered as public affairs management to promote the public interest and creating a belief in social responsibilities in organizations is the cornerstone of public affairs management. Also, Zeng, et al (2015), Masrinskiene, Macerinskienea and Balciunasb (2015), Ceil (2016) in their research have concluded that social responsibility can increase employee performance and ultimately lead to increased commitment. It also becomes their organization. Mihaela (2016) also stated in their research that without any legal obligation, ISO 26000 emphasizes and focuses on 7 key issues that need a synergistic approach to achieve its goals: governance, human rights, Labor, the environment, business practices, consumers, and society.

Given that the role of determining goals in social responsibility has been confirmed, it is therefore suggested that in order to achieve goals and achieve success, in the organization to draw a clear picture of their future, a picture that clearly defines the future orientations of the organization. And by creating the right vision in the organization, they produce such energy that by using the skills, talents and resources necessary to achieve it, they start to move towards the desired future by leaps and bounds. Also, by creating a clear relationship between work and organizational ideals, it creates compatibility of the method of doing work with fair operating principles and ultimately creates positive energy in the organization. On the other hand, it is suggested that by institutionalizing the social responsibility approach in organizational strategies and taking into account the expectations and interests of all organizational stakeholders in formulating the organization's mission, employees should participate in the realization of socially responsible organization as a common goal. 
The results of this study showed that technology has a direct and significant impact on socially responsible organization. Therefore, it is suggested that the organization, by creating innovation in technology, make employees eager to learn new technologies, increase staff speed in learning and use new technologies, and increase staff skills in various technologies, so that employees understand the importance of using Increase new technologies in the organization. It is also suggested that the technologies used in the organization be environmentally friendly. In this regard, the use of social media to obtain information and work knowledge and maintain and strengthen communication in order to advance the social goals of the organization is recommended.

The results of this study also showed that structure has a direct and significant effect on socially responsible organization. According to the results, it is suggested to increase team communication in the organization by paying attention to other colleagues in the work team, freely expressing opinions and participation of team members in decisions and employee support for actions leading to the growth of other employees in the card game space. . Also, by involving employees in decisions related to new programs and policies of the organization, to improve governance in the organization by the managers of the organization.

This study showed that individuals have a direct and significant impact on socially responsible organization. According to the obtained results, it is suggested that the managers of the organization pay special attention to the cultural attitudes that are created through the importance of organizational success compared to individual success, and the importance of individual rewards as much as organizational success. Also, the top managers of the organization have more commitment to the organization by doing work outside of work hours and strengthening the sense of closeness and belonging to the organization. This study shows that respectful behavior of the organization's personnel with citizens, lack of partisanship and bribery in the organization and elimination of gaps and legal problems regarding citizens 'issues and citizens' guidance to solve problems can create a suitable work environment for employees and citizens. Create in the municipality. Managers must also be accountable to citizens by providing information on the performance, implementation of the organization's policies and programs and providing appropriate services to them. So far, most research on social responsibility has focused on increasing organizational performance. While the destructive, inappropriate and wrong behaviors of the top managers of the organization can prevent the creation of a socially responsible organization in the organization and cause the failure of the best plans / projects. Therefore, it is necessary to study which style and what kind of behavior of top managers hinders the growth of socially responsible organization. 


\section{References}

Aghighi M, Torabian R. (2019) Ethics of business and work in Islam; Concepts, Specifics and Necessities, 5th International Conference on Accounting, Management and Business Innovation, Tehran.

Aluchna M. (2010). Corporate social responsibility of the top ten: examples taken from the Warsaw Stock Exchange. Social responsibility journal, 6 (4): 611-626.

Alvani S M, Ahmadi K. (2013) The concept of organizational social accountability and the need to explain its components in government organizations in Iran, Quarterly Journal of Management of Government Organizations, 1 (3).

Aslan Ş, Şendoğdu A. (2012) The Mediating Role of Corporate Social Responsibility in Ethical, 8th International Strategic Management Conference, Procedia - Social and Behavioral Sciences, 58: 693 - 702.

Avram E, Avasilcai S. (2014), Business Performance Measurement in Relation to Corporate Social Responsibility: A conceptual Model Development, 2nd World Conference On Business, Economics And Management-WCBEM 2013, Procedia - Social and Behavioral Sciences 109 ( 2014 ): 1142 - 1146

Barone M J, Miyazaki A D, Taylor K A. (2000). The Influence of Cause-Related Marketing on Consumer Choice: Does One Good Turn Deserve Another? Journal of the Academy of Marketing Science, 28(2): 62-248.

Ceil Ch. (2016). Employees and corporate social responsibility, Journal of Enviromental Management, 88(1): 817830.

Ferrell O C, Harrison Dana E. Ferrell L, Hair Joe F. (2020). "Business ethics, corporate social responsibility, and brand attitudes: An exploratory study," Journal of Business Research, Elsevier, 95(C): 491-501.

Ghavami H, Jafari Samimi A. (2020) Business ethics in brand attitude in Iran Khodro Company, Master Thesis, Rahe-Danesh University of Babol.

Hahn R. (2013). ISO 26000 and the Standardization of Strategic Management Processes for Sustainability and Corporate Social Responsibility, Published online 13 September 2012 in Wiley Online Library (wileyonlinelibrary.com)

Hajiha Z, Sarfaraz B. (2014), Investigating the relationship between social responsibility of security companies and equity assets in companies listed on the Tehran Stock Exchange, Empirical Accounting Research, 4 (14): 123-105.

Hans W. (2005) Desirable Social Behaviors from the Perspective of Social Psychology, translated by Rezvan Sedghinejad, Tehran, Gol Azin Publications.

Kaptein M, Kooning L, Tulder Rob V, Vliet Laurens V. (2017). Report on European CSR Survey, Holland, RSM Erasmus University.

Karaye Y I, Zuaini I, Noriah Ch. (2014) The mediating effect of stakeholder influence capacity on the relationship between corporate social responsibility and corporate financial performance, International Conference on Accounting Studies 2014, ICAS 2014, 18-19 August 2014, Kuala Lumpur, Malaysia, Procedia - Social and Behavioral Sciences, 164: $528-534$.

Kavaliauskè M, Stancikas A. (2014). The importance of corporate social responsibility in Lithuania's finance and telecommunication industries, Procedia - Social and Behavioral Sciences 110 ( 2014 ): 796 - 804.

Khajavand Ahmadi I, Sanaei M. (2016). an analysis of the social responsibility of the Ministry of Oil and Sustainable Development of the city, as well as the social responsibility of the Oil Industry Society, Tehran, Institute of Management and Planning Research, University of Tehran.

Khodabakhshi M, Abedi M R. (2009). "Study of methods to increase self-confidence in middle school students in Shahreza in the academic year 2005-2006", Quarterly Journal of Psychological Studies, Al-Zahra University, 5 (1).

Kunda G A, Nihal K B. (2019) "Corporate socialresponsibility and organizational citizenship behavior: The mediating role of job satisfaction", Journalof Global Responsibility, 10(1): 47-68.

Macerinskienea I, Balciunasb A. (2015) The evidence of social responsibility in foreign exchange brokers' activities, 20th International Scientific Conference Economics and Management - 2015 (ICEM-2015), Procedia - Social and Behavioral Sciences 213 (2015): 552 - 556.

Majidi Ghahroudi Y, Javadieh Z. (2011) Investigating the role of organizational communication for the formation and absorption of social capital, Journal of Communication Culture, 4: 165-190.

Mihaela H. (2016). ISO 26000 - AN INTEGRATIVE APPROACH OF CORPORATE SOCIAL RESPONSIBILITY, Studies in Business and Economics no. 11(1). 
Nasiri F. (2014) Relationship between Perceived Organizational Support of Urban Management and Social Responsibility and Job Performance of Hamadan Municipality Employees Quarterly Journal of Urban Economics and Management, 8(3).

Rigoberto Parada D J. (2016) A valuation model for corporate social responsibility, 5 (3): 284-299.

Royaei R, Mehrdoust H. (2015). Investigating the Cultural Role in Promoting Social Responsibility: A Study of the Broadcasting Technique, Journal of Social Sciences, 3 (3): 43-59

Saedi S, Khalatbari J, Najafabadi N. (2014). "The Relationship between Quality of Work Life and Organizational Health with Job Satisfaction", Quarterly Journal of Industrial / Organizational Science Psychology, 1 (4).

Sarlak M A. (2012), Emerging Figures of the Organization in the 21st Century, Knowledge Reference Publishing, Tehran, 2.

Shafei R, Azizi N. (2013) Study of social organizational status in universities and higher education centers in the west of the country (design of an experimental model), Constructive Journal of Education, 1 (2).

Shariatmadari M. (2009). "" Study of the relationship between organizational health and the effectiveness of management schools in Tehran ", Quarterly Journal of Educational Sciences, 2 (6).

Sheikhi M H. (2015). "Factors affecting administrative health and the growth of ethical values in it", Journal of Islam and Management Research, 1 (2).

Talebi A, Khoshbin Y. (2012) "Youth Social Responsibility", Social Sciences Quarterly, 59.

Tawfiqi Sh, Chaqeri M, Amerion A, Karimi Zarchi A A. (2015). "The effect of organizational changes on organizational health indicators and its relationship with organizational effectiveness", Journal of Roghayeb Medicine, 13 (3).

Übius Ü, Alas R. (2009). Ruth Alas Organizational Culture Types as Predictors of Corporate Social Responsibility. Engineering Economics; 4(61): 90-99.

Wahba H, Elsayed Kh. (2015) The mediating effect of financial performance on the relationship between social responsibility and ownership structure, Future Business Journal, 11 (2015): 1-12.

Yousefi R, Fattahi M. (2020) is expected to have general social responsibility in case of social responsibility in Behpak Behshahr Company, Master Thesis of Islamic Azad University, Sari Branch.

Zeng S X, Zeng Vivian W Y. (2015), Social responsibility of major infrastructure projects in China, International Journal of Project Management 33 (15): 537-548. 